\title{
Revisión de las tecnologías avanzadas para la producción de butanol: un biocombustible alternativo.
}

\section{Review of advanced process technologies for butanol production: an alternative biofuel.}

\author{
Víctor Hugo Grisales-Díaz \\ ${ }^{1,2,3}$ Universidad Nacional de Colombia, Bogota - Colombia
}

Recibido: 06 de julio de 2020.

Aprobado: 31 de octubre de 2020.

Resumen - El butanol es un biocombustible alternativo al etanol con más alto rendimiento energético y menos corrosivo. La principal ventaja de la producción biológica de butanol es la capacidad de fermentar tanto hexosas como pentosas, lo que lo hace una ruta atractiva para la valorización de residuos biomásicos. No obstante, esta fermentación en procesos convencionales tiene una baja productividad y concentración de producto, es decir, tiene una elevada inversión de capital y requerimientos de energía. Por tal motivo, en esta revisión se analizan las ventajas y desventajas de las diferentes tecnologías alternativas para la producción biológica de butanol. Entre las posibles tecnologías, se estudió la fermentación en etapas usando dos tipos diferentes de microrganismos, sistemas de recuperación in situ, sistemas con recirculación de biomasa e inmovilización celular. Una sola tecnología por sí sola no es capaz de solventar los bajos coeficientes de desempeño de la fermentación. Por lo cual, solo a través de diseños que combinen estas tecnologías se será capaz de volver la producción biológica de butanol grande otra vez. Entre las posibles combinaciones para valorizar los residuos lignocelulósicos, sistemas integrados con evaporación a vacío o con sistemas extractivos con solventes, con producción previa de ácido láctico y recirculación de biomasa, son interesantes ya que permiten alcanzar rendimientos cercanos al teórico, pueden incrementar la productividad en más de dos veces y tiene requerimientos de energía relativamente bajos (7-8 MJ/kg).

Palabras Claves: reactores con recuperación in situ, valorización de biomasa, fermentación ABE, recirculación de biomasa, intensificación de procesos.

Abstract - Butanol is an alternative biofuel to ethanol with higher energy efficiency and is less corrosive. The main advantage of the biological production of butanol is the ability to ferment both hexoses and pentoses, making it an attractive route for valorization of biomass residues. However, this fermentation in conventional processes has low productivity and product concentration, which means that both capital costs and energy requirements are high. Hence, this review analyzes the advantages and disadvantages of alternative technologies for the biological production of butanol. Between the possible technologies, we analyzed fermentation in stages using two different types of microorganisms, in situ product recovery and biomass recirculation. A single technology by itself is not capable of solving the low-performance indicators of the fermentation. Therefore, biological production will be great again with designs that integrates these technologies. Among the possible combinations to valorize lignocellulosic residues, integrated systems with vacuum evaporation or with extractive systems with solvents, with a previous lactic acid production and biomass recirculation, are interesting as yields are closed to the theoretical and the productivity can be increased more than twofold with low energy requirements $(7-8 \mathrm{MJ} / \mathrm{kg}$ ).

Keywords: in situ recovery reactors, biomass valorization, ABE fermentation, biomass recycle, process intensification. 


\section{INTRODUCCIÓN}

Alrededor de 1950, la transformación biológica de butanol llegó a ser el segundo proceso fermentativo más significativo, solo siendo superado por la producción biológica de etanol [1]. La producción biológica de butanol es conocida como fermentación ABE ya que además de butanol se producen dos subproductos principales, la acetona y el etanol. Con la aparición de los métodos de producción por ruta petroquímica, sumado a los bajos indicadores de desempeño de la producción biológica de butanol, la mayoría de las plantas con una escala industrial cerraron en los años 80 [1]. En el mercado actual, este alcohol tiene una demanda mundial mayor a seis mil millones de dólares [2]. El butanol es considerado un biocombustible alternativo al etanol, ya que es menos corrosivo y tiene un mayor rendimiento energético; es decir, se avanzan más kilómetros por litro usando butanol en comparación a cuando se usa etanol. Por este motivo, diferentes empresas petroquímicas y biotecnológicas y algunas spinoff han enfocado sus esfuerzos en volver rentable, de nuevo, la producción de butanol [3]. Lo anterior ocasiono que la producción biológica de butanol sea reintegrada en fábricas de China y Brasil [3].

La transformación biológica para la producción de butanol es realizada por diferentes cepas nativas, siendo las principales Clostridium saccharobutylicum, C. saccharoperbutylacetonicum, C. acetobutylicum y C. beijerinckii [4]. Estas bacterias son anaeróbicas estrictas, mesófilas y gram positivas. Adicionalmente, tienen la capacidad de consumir diferentes sustratos con rendimientos de solventes cercanos al teórico [1], lo cual es la principal ventaja para su uso. Entre los sustratos que pueden transformar eficientemente, encontramos la glucosa, sacarosa, dextrina, fructosa, manosa, lactosa, almidón, glicerol, xilosa, y arabinosa [1]. Escoger cual es el mejor microorganismo para la producción de butanol es complejo y dependerá del proceso usado, ya que estos microrganismos tienen diferentes índices de desempeño y estos índices dependen tanto del sustrato como del tipo de reactor usado. En términos generales, usando la bacteria C. acetobutylicum 260 alcanza la más alta productividad, conversión de sustratos y rendimiento $\mathrm{ABE}$ con una mezcla de pentosas y hexosas como sustratos [5], [6], mientras C. butylicum NRRL 592 alcanza el más alto consumo de xilosa [5], [6]. Por otro lado, con la cepa C. beijerinckii BA101 se alcanza la más alta selectividad y concentración final de butanol [7]. Otros autores, consideran que C. saccharoperbutylacetonicum es una de las cepas más robustas porque consume ambos, hexosas y pentosas, con un alto rendimiento y productividad [8], [9].

La producción biológica de butanol usando estas cepas nativas tiene dos fases metabólicas y para la conversión de los carbohidratos necesita más de 90 genes [10]. La acidogénesis es la primera fase y se generá el crecimiento exponencial. En esta fase exponencial de crecimiento, se produce la mayor cantidad de energía (una ganancia neta de 3.5 de ATP por mol de glucosa) de hidrógeno y de ácidos orgánicos, tales como el ácido acético, butírico y láctico. En la segunda fase, solvento-génesis, se da el crecimiento estacionario y la conversión de los ácidos en los solventes (acetona, butanol y etanol). En esta fase, se da una ganancia de 2 de ATP por mol de glucosa. Debido a la mayor concentración de ácidos, en la acidogénesis el pH pasa de valores entre 6.5 a 7.0 a valores entre 5.0 a 4.5. En la solventogénesis, el $\mathrm{pH}$ se incrementa de nuevo a valores cercanos a 7.0.

Los solventes y ácidos son tóxicos para el microorganismo que los produce. Aunque la solventogenesis atenúa la toxicidad de los ácidos al ser una respuesta de adaptación de estas bacterias al bajo $\mathrm{pH}$ o a la alta concentración de ácidos [11], cuando la concentración de butanol llega a niveles entre 12 a 16 g L-1 se alcanza una inhibición total de la fermentación [12]. Es importante mencionar que cuando las concentraciones de butanol son más bajas que 4 - 4.8 g L-1, no se observa una inhibición por butanol [1]. Los compuestos menos tóxicos en la fermentación son acetona y etanol. Por ejemplo, el etanol y acetona solo reducen el crecimiento en $50 \%$ cuando las concentraciones son alrededor de $40 \mathrm{~g} \mathrm{L-1}$ [13]. Debido a que el butanol es el producto principal e inhibe la fermentación totalmente a concentraciones menores que $20 \mathrm{~g} \mathrm{~L}-1$, estas concentraciones de etanol y acetona no se alcanzan en la fermentación. En consecuencia, el butanol es el compuesto que llega a concentraciones más inhibitorias en la fermentación.

Los microorganismos modificados genéticamente han sido desarrollados en épocas recientes para disminuir la producción de subproductos e incrementar la tolerancia de butanol a altas concentraciones. Para tal fin, varios microorganismos no nativos han sido usados, entre los cuales encontramos S. cerevisiae [14], Lactobacillus brevis [15], [16], Scherichia coli [17]-[22], Pseudomonas putida [23], [24] y Bacillus subtilis [24], [25]. Los cuales son diseñados para producir exclusivamente iso-butanol o nbutanol. En comparación, el iso-butanol inhibe menos la fermentación [26]. Adicionalmente, es un atractivo biocombustible. En su uso como químico, la principal desventaja del iso-butanol es que no puede remplazar de manera total los usos del n-butanol [26], [27]. Una desventaja adicional de estos microorganismos, es que no convierten la gran variedad de azúcares que si son capaces de metabolizar las cepas nativas [26].

La valorización de residuos biomásicos es una alternativa interesante al uso de sustratos convencionales, debido a la capacidad de las cepas nativas de consumir una gran variedad de azúcares. De esta manera, se usan sustratos más económicos y se resuelve el manejo de estos residuos, generando un valor agregado. En la fermentación $\mathrm{ABE}$, el factor más importante es el costo del sustrato y el bajo rendimiento de butanol [1], [28], [29]. Por ejemplo, si se incrementa el rendimiento de butanol hasta de $42 \%$ a $50 \%$, los costos se reducen en $\sim 15 \%$ (de 0.34 a 0.29 \$USD/kg) [30]. En este sentido, sustratos alternativos a los convencionales (jugo de caña, melaza y granos de maíz) han sido propuestos. Entre estos sustratos encontramos, aguas residuales domésticas [31], [32]; residuos de agricultura tales como el la fibra de maíz, rastrojo de maíz, los granos secos de destilería con solubles [6], [33], [34] la paja de cebada [35], paja de trigo [36]; pulpa de manzana [37]; maní [38]; papa [39]; glicerol [40], alcachofa [41], y microalgas [42], [43].

Para incrementar los bajos indicadores de desempeño de la fermentación, tales como, la baja concentración de producto y la baja productividad, se han propuesto diferentes alternativas ingenieriles de producción. Los procesos convencionales de producción industrial son el lote ("batch") y reactores continuos los cuales son operados en serie. En reactores en lote y con C. beijerinckii BA101, se ha logrado la concentración máxima de $\mathrm{ABE}$ la cual es de $33 \mathrm{~g} \mathrm{~L}-1$ con un rendimiento de 0.4-0.42 gg-1 [44], [45]. Debido a la inhibición por producto, el sustrato es alimentado a estos reactores a concentraciones menores que 60 - $80 \mathrm{~g} \mathrm{~L}-1$ [46]. El tiempo de fermentación final en un reactor en lote es de 48 y $96 \mathrm{~h}$. En la industria, los reactores en serie en continuo son más utilizados debido a sus mayores productividades (>20\%) [47]. El número de los reactores en la serie son entre 3 y 8 [48]. El sustrato es puesto en la autoclave a $121^{\circ} \mathrm{C}$ por 15 minutos con un enfriamiento posterior entre $35-37{ }^{\circ} \mathrm{C}$ e inoculación con el microrganismo de la fermentación. Durante el enfriamiento, se burbujea $\mathrm{N} 2$ o $\mathrm{CO} 2$ para alcanzar las condiciones anaerobias necesarias en la fermentación. Una vez se alcanza el tiempo de fermentación final, la biomasa y los sólidos son recuperados usando centrifugación. Estos sólidos son usualmente vendidos como alimento de ganado. Las alternativas ingenieriles que han sido desarrolladas en la literatura a estos procesos convencionales serán discutidas a en las próximas secciones con más detalle.

\section{RECICLO E INMOVILIZACIÓN CELULAR}

La velocidad de producción está directamente relacionada con la concentración de microorganismos (biomasa celular). Por lo cual, algunas tecnologías están enfocadas en incrementar la productividad 
del reactor buscando primero incrementar la concentración de células en el reactor. Incrementar la productividad es importante porque altas productividades indican bajos volúmenes de reacción y por ende menor inversión de capital en el sistema de reacción. Para tal fin, los reactores con recirculación celular o inmovilización son usualmente empleados [49]-[53].

En los reactores con recirculación celular se recomienda usar un sistema de microfiltración con purga para alcanzar más altos tiempos de operación. Estos sistemas evitan la acumulación de otros sólidos en el reactor, los cuales pueden inhibir la fermentación. Adicionalmente, altas concentraciones de biomasa hacen más difícil el control del volumen del reactor debido a la mayor velocidad producción de los gases de fermentación (dióxido de carbono e hidrogeno). Por ello, la concentración de biomasa en el reactor debe ser menor que $30 \mathrm{~g} \mathrm{~L}-1$. Usando este método se han alcanzado productividades ABE de $7.65 \mathrm{~g}$ L-1 h-1 y concentraciones ABE de 8.58 g L-1 [52], con altos tiempos de fermentación $(>200$ h).

En los biorreactores con inmovilización celular se ha logrado la máxima productividad reportada en la síntesis de butanol, $15.8 \mathrm{~g} \mathrm{l-1}$ h-1. Siendo estable por cerca de 550 horas. No obstante, esta alta productividad fue alcanzada con bajas conversiones de sustrato $(33 \%)$ y bajas concentraciones ABE, $7.9 \mathrm{~g} \mathrm{~L}-1$ [51].

Los reactores con recirculación de biomasa incrementan la productividad del reactor convencional en lote entre 16 y 30 veces. Sin embargo, disminuyen otros indicadores de desempeño de la fermentación, como lo son la conversión de sustrato y concentración de producto. Como alternativa para solucionar este problema, se han propuesto reactores en dos o más etapas con reciclo o inmovilización celular. Este tipo de sistemas de reacción permite llevar a cabo de manera separada la acidogénesis y solventogénesis, lo que disminuye la degeneración celular. En un sistema de reacción con dos etapas y usando C. acetobutylicum DSM 1731, se han alcanzado altas concentraciones de solventes, $18.2 \mathrm{~g} \mathrm{~L}-1$, y productividades, $1 \mathrm{~g} \mathrm{~L}-1$ h-1 [54]. En este sistema, se logra duplicar la productividad con concentraciones equivalentes de solvente [54].

\section{REACTORES CON RECUPERACIÓN IN SITU DE PRODUCTO}

La eficiencia energética de la separación depende la concentración final que se alcanza en el reactor. Por ejemplo, usando destilación, si se incrementa la concentración de producto final de 10 a $40 \mathrm{~g} / \mathrm{l}$ se reduce el combustible requerido en la separación en un 80\% [55]. Por tal motivo, se han propuesto reactores con recuperación in situ de producto, los cuales incrementan tanto la concentración de producto como la productividad. Estos sistemas integrados de reacción y separación limitan la toxicidad de butanol e incrementan la concentración final de butanol, lo cual permite incrementar la concentración de sustrato alimentada. Alimentar mayores concentraciones de sustrato es importante porque el consumo de agua en los procesos y los requerimientos energéticos corrientes arriba y abajo se reducen [56].

Los reactores integrados mejoran la productividad y concentración de producto. Sin embargo, no necesariamente incrementan el rendimiento de producto. Esto puede ser observado en la Figura 1, en la cual se muestra que no existe una relación entre incrementar la productividad y aumentar el rendimiento para diferentes reactores con recuperación [51], [57], [66]-[71], [58]-[65].

Entre las técnicas de recuperación propuestas en reactores con recuperación in situ, se encuentran las siguientes tecnologías de separaración: la evaporación a vacío, la pervaporación, el gas de arrastre, la extracción liquido líquido y la pertracción. Las cuáles serán descritas en más detalle a continuación:

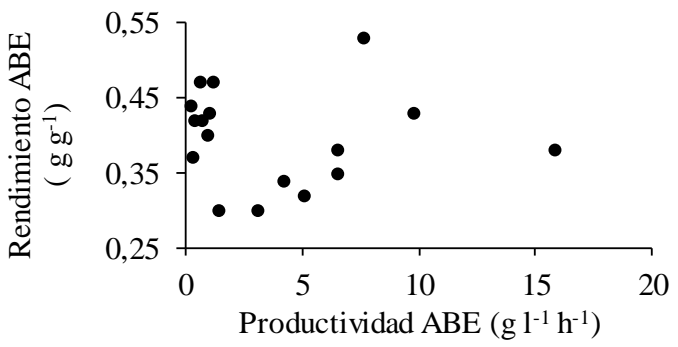

Figura 1: Relación entre productividad y rendimiento en la fermentación usando diferentes técnicas de recuperación, cepas y modos de operación [51], [57], [66]-[71], [58]-[65].

Fuente: Elaboración propia.

\section{a) Gas de arrastre}

En la fermentación con recuperación in situ de producto por gas de arrastre, los gases de la fermentación son burbujeados en el reactor con el objetivo de arrastrar los solventes volátiles. Un diagrama de esta tecnología se observa en la Figura 2. La selectividad con la que son removidos los solventes volátiles orgánicos (acetona, butanol y etanol) varía entre 4.5-30.5 [72].

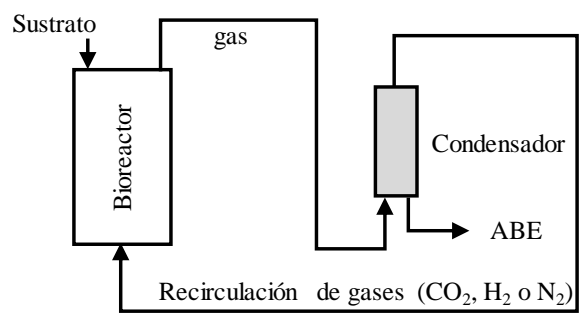

Figura 2: Esquema de un rector con recuperación in situ de producto con gas de arrastre.

Fuente: Elaboración propia.

En reactores operados con alimentación de sustrato en lote e integrados con gas de arrastre, se han usado concentraciones de lactosa

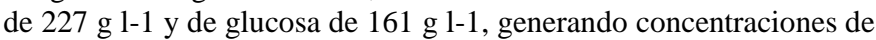
$\mathrm{ABE}$ de 137 y $76 \mathrm{~g} \mathrm{~L}-1$, respectivamente [63]. Las cuales son concentraciones de sustrato entre 3 y 4 veces más altas a las usadas en reactores convencionales.

Alternativamente, modos de operación semicontinuos son propuestos con la meta de reducir la inhibición de sustrato que sucede a altas concentraciones. En este sistema, se mantienen las concentraciones de sustrato a valores más bajos que 60 y 100 g L-1. Este método de operación permite alcanzar concentraciones ABE de 233 g L-1 [60]. Adicionalmente, debido a la menor inhibición de sustrato y producto, se alcanzan productividades de hasta $1.16 \mathrm{~g} \mathrm{~L}-1$ $\mathrm{h}-1$. Es decir, se puede incrementar la productividad 4 veces e incrementar la concentración de producto más de 10 veces. Una de las mayores ventajas de esta tecnología son sus altos rendimientos de producto [59]. Una de las razones a las que puede ser atribuido este comportamiento, es por el reciclo y consumo de hidrógeno y dióxido de carbono para producir los solventes [60].

\section{b) Extracción líquido-líquido}

Las tecnologías de extracción líquido-líquido necesitan de un solvente orgánico. Con estos reactores, se puede incrementar la productividad hasta 6.2 veces [62]. Un esquema de fermentación extractiva in situ de producto es observado en la Figura 3. En esta técnica, el extractante no puede ser tóxico para que pueda ser mezclado con el medio de fermentación. Este extractante puede ser recuperado por decantación [62], [73]-[78]. Una vez recuperado, el butanol es separado del extractante mediante destilación. 


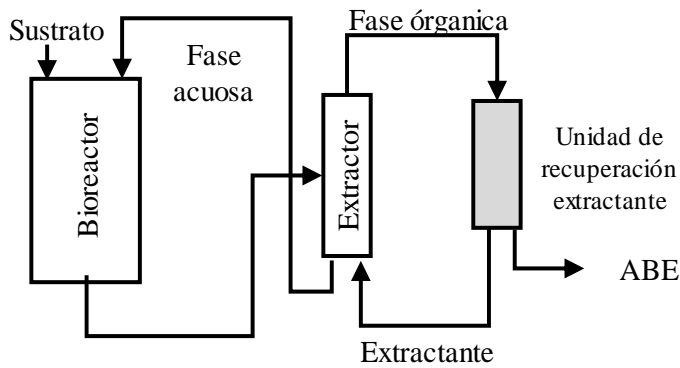

Figura 3: Sistema de reacción con recuperación in situ de producto con equilibrio líquido-líquido.

Fuente: Elaboración propia.

Los sistemas de extracción pueden ser ex situ o in situ [79]. En la extracción in situ, el control es más difícil, la inhibición celular por el extractante es mayor, los coeficientes de reparto de los solventes no tóxicos son más bajos y existe una mayor recuperación de ácidos orgánicos [56], [80], [81]. Diferentes solventes han sido estudiados en la literatura, con el objetivo de encontrar solventes con alto coeficiente de recuperación y selectividad [77], [82]. En la Tabla 1, se reportan algunos de los coeficientes de separación de varios solventes orgánicos.

Tabla 1: Solubilidad (S) y coeficientes de reparto $(\mathrm{m})$ a $25^{\circ} \mathrm{C}$ y $1 \mathrm{~atm}$ para la recuperación de butanol con diferentes solventes ${ }^{\mathrm{a}} 20^{\circ} \mathrm{C} \mathrm{b}[87]^{\mathrm{c}}[84]^{\mathrm{d}}$ a $22^{\circ} \mathrm{C}$, ${ }^{\mathrm{e}}$ estimada a partir de la selectividad, ${ }^{\mathrm{f}} 36^{\circ} \mathrm{C}$

\begin{tabular}{|c|c|c|c|c|c|}
\hline Solvente & $\begin{array}{c}\mathrm{S}_{\mathrm{BuOH}}^{\mathrm{org}} \\
{\left[\mathrm{g} \mathrm{L}^{-1}\right]^{\mathrm{b}}}\end{array}$ & $\begin{array}{c}\mathrm{S}_{\mathrm{H}_{2} \mathrm{O}}^{\mathrm{aq}} \\
{\left[\mathrm{g} \mathrm{L}^{-1}\right]^{\mathrm{b}}}\end{array}$ & $m_{\mathrm{H}_{2} \mathrm{O}}^{\text {org } / a q}$ & $m_{\text {BuOH }}^{\text {org } / a q}$ & Referencia \\
\hline Octano & & $7.3 \times 10^{-4}$ & $7.2 \mathrm{E}-05$ & 0.30 & [73], [83] \\
\hline $\begin{array}{l}\text { aceite de } \\
\text { sésamo }\end{array}$ & & & $1.3 \mathrm{E}-03$ & 0.30 & [73] \\
\hline aceite de olivo & $\infty$ & 0.0098 & $\begin{array}{c}1.48 \mathrm{E}- \\
03\end{array}$ & 0.71 & [73] \\
\hline oleato de etilo & & & 0.22 & 1.3 & [73] \\
\hline $\begin{array}{l}\text { ftalato de } \\
\text { dibutilo }\end{array}$ & & & 0.47 & 1.4 & [73] \\
\hline $\begin{array}{l}\text { laurato de } \\
\text { metilo }\end{array}$ & & 0.0112 & 0.26 & 1.8 & [73] \\
\hline Triclorometano & & 8.0 & & 2.8 & [83] \\
\hline $\begin{array}{l}\text { maleato de } \\
\text { dibutilo }\end{array}$ & & & 0.66 & 2.0 & [73] \\
\hline aceite de castor & & $15.9^{\mathrm{a}}$ & $\begin{array}{c}9.55 \mathrm{E}- \\
03\end{array}$ & 2.6 & [73] \\
\hline $\begin{array}{l}\text { acetato de } \\
\text { hexilo }\end{array}$ & & $0.2 \mathrm{a}$ & 0.72 & 3.6 & [73] \\
\hline Dodecanol & & $4 \times 10-3$ & 0.04 & 6.0 & {$[73]$} \\
\hline éter dietílico & $\infty$ & 64.2 & & 7.8 & [83] \\
\hline Octanol & $\infty$ & 0.54 & 0.078 & 7.6 & [73], [83] \\
\hline Hexanol & & 6 & 0.076 & 12 & [73] \\
\hline$[$ Omim $][\mathrm{Tf} 2 \mathrm{~N}]$ & & $9 \times 10^{-5 c}$ & 0.018 & 1.4 & {$[84]$} \\
\hline$[\mathrm{Hmim}][\mathrm{Tf} 2 \mathrm{~N}]$ & & $2.3 \times 10^{-3 \mathrm{c}}$ & 0.019 & 1.3 & [84] \\
\hline [Omim][PF6] & & $1.5 \times 10^{-3 \mathrm{c}}$ & 0.023 & 1.1 & [84] \\
\hline$[\mathrm{Omim}][\mathrm{Tf} 2 \mathrm{~N}]$ & & & 0.018 & 1.4 & {$[85]^{\mathrm{d}}$} \\
\hline$[\mathrm{Omim}][\mathrm{BF} 4]$ & & & 0.179 & 2.2 & {$[84]$} \\
\hline alcohol oleico & 15.4 & $7 \times 10^{-5}$ & 0.02 & 3.0 & {$[78]$} \\
\hline 2-etil-1-hexanol & & & $0.025^{\mathrm{e}}$ & $\sim 8.0$ & [86]f \\
\hline
\end{tabular}

Fuente: Elaboración propia.

Un alto coeficiente de reparto es deseado ya que se debe usar una menor cantidad de solvente para alcanzar el nivel de separación deseado. Adicionalmente, altos coeficientes de recuperación permiten reducir los requerimientos energéticos en la recuperación del extractante en el sistema de destilación [88]. Por otro lado, altas selectividades reducen el contenido de agua la fase orgánica y se pueden alcanzar mayores concentraciones de producto. El 2-etil-1hexanol es uno de los solventes con mayor coeficiente de reparto y selectividad. A pesar de sus ventajas, este solvente ha sido encontrado tóxico para C. acetubutylicum e inhibe totalmente el proceso concentraciones tan bajas como $5 \mathrm{wt} \%$ [82]. El alcohol oleico es uno de los más usados por su biocompatibilidad en sistemas de reacción in situ, pese a sus coeficientes de reparto y selectividades intermedios. Una ventaja adicional del alcohol oleico es su capacidad de extraer inhibidores generados en el petratamiento físico-químico del material lignocelulósico [88]. Con una purificación final por destilación, este sistema con detoxificación simultanea permite generar un valor agregado adicional, debió a la producción simultanea de furfurol y compuestos fenólicos.

\section{c) Pertracción}

En la pertracción, las dificultades de la extracción líquido - líquido in situ pueden ser solucionados usando una membrana que evite el contacto entre el solvente y el medio de fermentación. La membrana proporciona la superficie que separa el extractante del medio de fermentación. Las membranas usadas en este tipo de fermentadores tienen un tamaño de poro entre 10000 y 100000 Dalton. Al eliminarse el contacto directo entre las dos fases, se pueden usar extractantes con altos coeficientes de reparto, los cuales pueden tener una alta toxicidad para los microorganismos de la fermentación. Adicionalmente, la formación de emulsiones es drásticamente reducida. Un esquema de integrado de fermentación y pertracción puede ser observado en la Figura 4

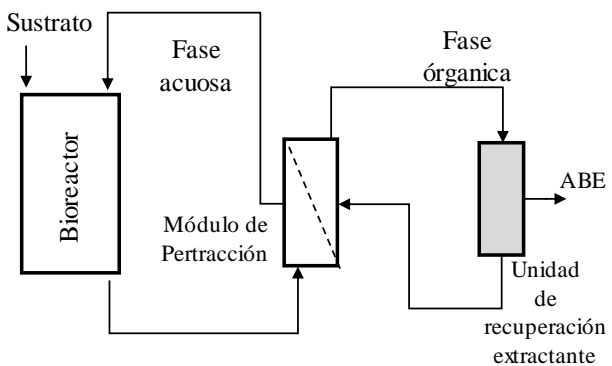

Figura 4: Sistema de reacción con recuperación in situ de producto por pertracción.

Fuente: Elaboración propia.

Debido a que los extractantes orgánicos tienen mayor compatibilidad con el butanol, este difunde por la membrana, mientras que el ácidos orgánicos permanecen en la fase acuosa [63]. Adicional al coeficiente de reparto, la velocidad de recuperación del medio de fermentación depende de la permeabilidad de la membrana. En consecuencia, la membrana es una barrera física que disminuye la velocidad de extracción del butanol.

Aunque el 2-etil-1-hexanol no puede ser utilizado directamente en sistemas de extracción líquido-líquido, si puede ser usado en esquemas de reacción integrados con pertracción. En estos reactores se ha logrado incrementar la productividad hasta en un $40 \%$ [82]. La pertracción es una técnica no madura, por lo tanto aún se necesitan evaluaciones técnicas y económicas más detalladas [89].

\section{d) Adsorción}

Un esquema de un sistema de reacción con recuperación in situ con adsorción se observa en la Figura 5. Para su aplicación en el medio de fermentación es necesario disminuir el ensuciamiento. Lo cual es importante porque el ensuciamiento reduce la capacidad de adsorción del butanol. El ensuciamiento se puede reducir usando sistemas de reciclo o inmovilización de biomasa ya que éstos disminuyan el contenido de solidos en el sistema de adsorción [90]. Utilizando polivinil-piridina como adsorbente en reactores con recuperación in situ se han alcanzado un rendimiento de $0.32 \mathrm{~g} \mathrm{~g}-1$, y una productividad de $1.69 \mathrm{~g} \mathrm{~L}-1 \mathrm{~h}-1$ [50]. Es decir, se ha incrementado la productividad en más de tres veces con una reducción en $20 \%$ del rendimiento. El rendimiento pudo haber disminuido debido a la adsorción de intermediarios de la fermentación, i.e. ácidos orgánicos. En la regeneración de adsorbente, si se realiza un calentamiento gradual o en etapas de la silicalita- 1 se pueden obtener concentraciones de butanol hasta 790 - 810 gL-1 lo que permite alcanzar un requerimiento de energía de $8 \mathrm{MJ} / \mathrm{kg}$ [90]-[92]. 


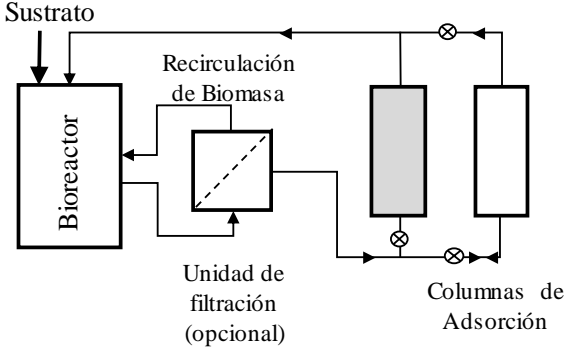

Figura 5: Configuración de un reactor con recuperación in situ por adsorción.

Fuente: Elaboración propia.

Existen diferentes adsorbentes estudiados en la literatura, los cuales buscan tener una mayor capacidad de adsorción y selectividad, ver Tabla 2. El carbón activado es el adsorbente con la mayor capacidad de adsorción para la recuperación de butanol (0.25 gg-1) (ver Tabla 2); no obstante, su estabilidad es baja debido a que el ensuciamiento y su regeneración del carbón activado es menos favorable que la silicalita [93]. Una alta estabilidad es deseada para los procesos industriales ya que las condiciones de operación de los equipos buscan ser uniformes. XAD-8 fue escogido por [93] como el mejor adsorbente, por su bajo ensuciamiento con los compuestos del medio de fermentación. Una de las limitaciones del XAD-8 es su baja selectividad (10). Debido a su baja selectividad, este sistema integrado de producción necesita un más grande consumo de energía $(33 \mathrm{MJ} / \mathrm{Kg})$ que cuando se usa destilación. En comparación, las silicalitas tienen selectividades entre 130-630 [93], las cuales son entre 13 y 63 veces mayores a la de XAD-8. Una limitación de esta tecnología con el uso de adsorbentes a base silica son los altos costos de capital debidos al alto costo de este adsorbente $(500 \$ / \mathrm{Kg})$ [90].

Tabla 2: Capacidad de adsorción de butanol.

\begin{tabular}{|l|c|c|c|}
\hline Adsorbente & $\begin{array}{c}\text { Tempera } \\
\text { tura }(\mathbf{O} \text { C) }\end{array}$ & $\begin{array}{c}\text { Capaci } \\
\text { dad } \\
\left(\mathrm{gg}^{-1}\right)\end{array}$ & $\begin{array}{c}\text { Refer } \\
\text { encia }\end{array}$ \\
\hline Carbón animal & & 0.206 & {$[95]$} \\
\hline Carbón activado (granular) & & 0.13 & {$[95]$} \\
\hline Carbón, Norit W52 & 37 & 0.18 & {$[94]$} \\
\hline Carbón, Norit ROW 0.8 & 37 & 0.25 & {$[94]$} \\
\hline XAD 2 (Resina) & 37 & 0.05 & {$[94]$} \\
\hline XAD 8 (Resina) & 37 & 0.04 & {$[94]$} \\
\hline XAD 4 (Resina) & 25 & 0.083 & {$[96]$} \\
\hline XAD 4 (Resina) & 37 & 0.0975 & {$[94]$} \\
\hline Bonoporo & 25 & 0.074 & {$[96]$} \\
\hline XAD 7 (Resina) & 25 & 0.069 & {$[96]$} \\
\hline Bonopore nitratado & 25 & 0.055 & {$[96]$} \\
\hline Polivinil-piridina & & 0.068 & {$[97]$} \\
\hline Silicalita & 20 & 0.097 & {$[92]$} \\
\hline Ssilica gel & 20 & 0.15 & {$[98]$} \\
\hline Silicalita & 25 & 0.048 & {$[99]$} \\
\hline
\end{tabular}

Fuente: Elaboración propia.

\section{e) Pervaporación}

La pervaporación permite a través del uso de membranas remover compuestos volátiles de la fermentación con una mayor selectividad (Figura 4). Los modos de operación de los reactores integrados con pervaporación pueden ser en lote, semi-continuos y continuos [57], [58], [100]-[105]. Usando pervaporación en reactores con recuperación in situ se ha logrado incrementar la productividad y la concentración de producto a 2.34 g L-1 h-1 [105] y 165 g L-1 [58]. Es decir, se ha aumentado el desempeño de la fermentación convencional alrededor de 5 y 8 veces la productividad y la concentración de producto, respectivamente.

Las membranas usadas en pervaporación no son tóxicas para el microorganismo y no remueven los nutrientes y ácidos orgánicos del medio de fermentación [106]. Adicionalmente, cuando se compara con gas de arrastre, no se generan emulsiones y se pueden alcanzar mayores productividades.

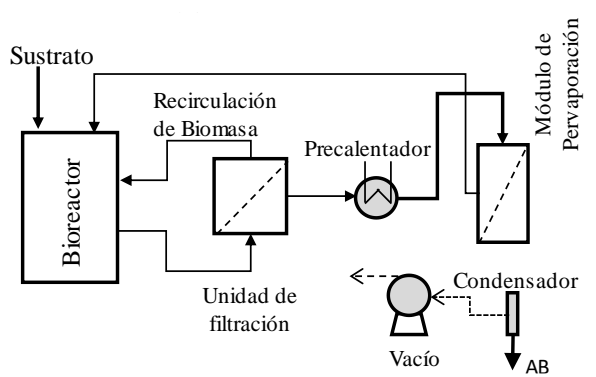

Figura 6: Configuración de un reactor con recuperación in situ por adsorción

Fuente: Elaboración propia.

La pervaporación ha sido reportada entre los sistemas de recuperación estudiados por Groot et al. (1992) con los menores requerimientos de energía, ver Figura 7. Por otro lado, Qureshi et al. (2005) reportó que ésta requiere el tercer menor consumo de energía, con $14 \mathrm{MJ} / \mathrm{Kg}$, [90], [107], ver Figura 7. La pervaporación y la adsorción son reportadas como las tecnologías de separación con menores requerimientos de energía por [93], $4 \mathrm{MJ} / \mathrm{Kg}$.

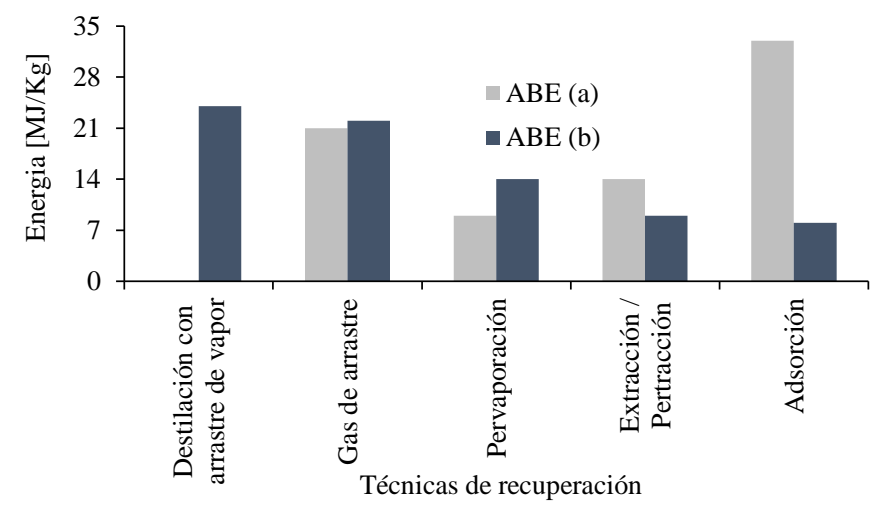

Figura 7: Requerimientos energéticos de diferentes reactores integrados en comparación con un sistema de destilación convencional (a) Referencia [90] (b) Referencia [107].

Fuente: Elaboración propia.

A pesar de los altos índices de desempeño (concentración de producto y productividad) y bajos requerimientos de energía, al ser una tecnología no madura, los siguientes aspectos deben ser estudiados en más detalle para una aplicación industrial más amplia [108]: aumento de la selectividad, integración de calor para aumentar la eficiencia energética, reducción del costo de las membranas y sus módulos, aumento del flux (flujo por unidad de área), pruebas de estabilidad de las membranas en largos periodos de tiempo en condiciones reales de operación, optimizar las condiciones de operación y análisis económicos detallados.

\section{f) Evaporación a vacío}

Entre las técnicas con recuperación in situ, pese a su simplicidad, la evaporación a vacío es una de las tecnologías menos estudiadas y conocidas en la literatura para la recuperación de butanol. Un esquema es observado en la Figura 8. La evaporación a vacío es una técnica de recuperación en la cual se disminuye la presión de vapor a presiones entre 0.05 y 0.07 bar, lo cual permite evaporar los solventes producidos en la fermentación [109]. Aunque el butanol tiene un punto de ebullición más alto que el agua $\left(118^{\circ} \mathrm{C}\right)$, la presencia de un azeótropo de punto de ebullición mínimo entre el agua y el butanol permite que el butanol a bajas concentraciones tenga factores de separación tan altos como 20 . Aunque la evaporación a vacío tiene requerimientos energéticos más altos que la pervaporación, sus costos asociados son menores y la estabilidad del proceso es mayor [109]. 
Ya que esta técnica tiene altos requerimientos energéticos, diferentes alternativas han sido propuestas para disminuirlos [110]. Entre las posibles alternativas de integración energética, las bombas de calor han mostrado alcanzar los más bajos requerimientos de calor [111]. En una bomba de calor el vapor es comprimido para poder asî de esta manera suplir el calor de evaporación (ver Figura 8). De esta manera, los requerimientos de energía de este proceso dependen solamente del sistema de compresión. Adicionalmente, concentraciones tan altas como $\sim 400 \mathrm{~g} \mathrm{~L}-1$ han sido alcanzadas debido la condensación parcial una corriente acuosa en la bomba de calor [111]. Estás altas concentraciones son alcanzadas usando compresión y condensación en etapas. Lo que ha permitido reducir sus requerimientos de energía a 7 MJ/kg [47]. Reactores con operación a vacío han logrado duplicar la productividad del reactor [112].

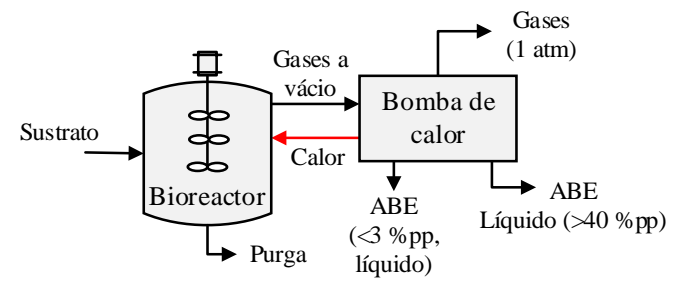

Figura 8: Sistema integrado de fermentación y evaporación a vacío con recuperación energética por destilación.

Fuente: Elaboración propia.

\section{IV.ALIMENTO ÁCIDO}

La producción biológica convencional de butanol tiene dos etapas claras, la acidogénesis y solventogénesis. Por lo cual, si se aumenta la producción de ácidos se espera un mejor desempeño de la fermentación, i.e. más alto rendimiento, productividad y concentración de producto. Es por tal motivo que se han diseñado procesos, donde un microorganismo especializado realiza la producción de los ácidos y en una segunda etapa los microorganismos especializados, la producción de butanol (i.e. C. acetobutylicum). Entre los posibles suplementos de la fermentación que pueden ser producidos por fermentación, encontramos el ácido acético, butírico, y láctico. Este tipo de procesos están patentados [68], [113]. A modo de ejemplo, en la producción de butanol con suplemento de ácido butírico se utiliza un sistema de reacción donde la conversión del sustrato al ácido butírico se da por Clostridium tyrobutyricum. En la segunda etapa de reacción se da el consumo de los ácidos producidos en la primera etapa por C. acetobutylicum o cepas similares. En este segundo reactor se alimenta glucosa porque una fuente de energía es necesaria para que se del consumo de los ácidos.

En estos procesos se ha observado que la adición ácido acético aumenta la concentración ABE [44]. Mientras, el ácido butírico incrementa la velocidad de síntesis de butanol reduciendo la cantidad de co-productos [114]. Finalmente, con el suplemento de ácido láctico se ha observado que se da un incremento del rendimiento, de la concentración y de la productividad de butanol [115]. Aunque estos procesos son prometedores, la eficiencia de estas tecnologías dependerá de la eficiencia para la producción de ácidos de los microorganismos especialistas en la síntesis de estos. Es por ello, que a continuación se describe cada uno de estos procesos en mayor detalle.

\section{a) Producción biológica de ácido acético}

El ácido acético se produce en reactores aerobios. Esta producción se da en dos etapas, en la primera etapa el sustrato se convierte en etanol usando la levadura Saccharomyces cereviseae. En una segunda etapa el etanol es oxidado a ácido acético usando Acetobacter. En este proceso se generan concentraciones de ácido acético de 12-14\%, alcanzando productividades entre 0.3 y $1 \mathrm{~g} \mathrm{~L}-1$ h-1 [116]. No obstante, esta producción biológica en comparación con la producción petroquímica no es viable debido a los altos costos de recuperación [116].

Alternativamente, el ácido acético es producido en reactores anaerobios usando cepas clostridias acetogénicas. Estas cepas pueden fermentar tanto hexosas como pentosas. La fermentación anaeróbia tiene tres ventajas en comparación con la conversión aeróbica [116]. En primer lugar, no se requieren los equipos y los requerimientos energéticos asociados para alimentar altas cantidades de oxígeno. En segundo lugar, la conversión anaeróbica puede alcanzar rendimientos de $100 \%$, siendo $30 \%$ mayor a la conversión aerobia. Finalmente, algunas de estas bacterias con capaces de convertir $\mathrm{CO} 2$, así mismo son capaces de convertir múltiples fuentes de carbono.

\section{b) Producción biológica de ácido butírico}

La producción biológica de ácido butírico, la cual se da en reactores anaerobios, tiene bajas productividades, rendimientos y concentraciones del producto [117]. Adicionalmente, una vez producidos, los ácidos orgánicos son difíciles de separar debido a su mayor punto de ebullición comparando con el agua. Por tanto, la producción petroquímica (la oxidación de butiraldehído) es la principal ruta para la producción de ácido butírico.

Diferentes microorganismos han sido evaluados para la conversión de azúcares a ácido butírico, tales como Sarcina, Clostridium, Butyrvibrio, Butyribacterium, Fusobacteriumy, Megasphera o Eubacterium [118]. Las bacterias Clostridium que son capaces de producir ácido butírico como producto principal son, $C$. butyricum, $C$. populeti, $C$. beijerinckii, $C$. tyrobutyricum y $C$. thermobutyricum [117]. Estos microorganismos producen como subproductos principales dióxido de carbono, hidrógeno, acetato y trazas de lactato. El rendimiento teórico máximo para producción de butanol es $0,67 \mathrm{~g} \mathrm{~g}^{-1}$ [119] debido a la coproducción de $\mathrm{CO}_{2}$.

La operación en continuo es usualmente realizada en reactores con inmovilización celular de lecho fijo (FBB) [75], Tabla 3. sando sistemas FBB con dos etapas ha alcanzado una productividad de $4.6 \mathrm{gL}^{-1} \mathrm{~h}^{-1}$. Este sistema produce butanol con una productividad 9.2 veces mayor al sistema convencional.

Tabla 3: Desempeño de un reactor inmovilizado (FBB) usando $C$. tyrobutyricum en a $37^{\circ} \mathrm{C}$

\begin{tabular}{|c|c|c|c|c|c|c|}
\hline \multirow[t]{2}{*}{ Sustrato } & \multirow[t]{2}{*}{$\mathrm{pH}$} & \multirow{2}{*}{$\begin{array}{l}\text { Productividad } \\
\qquad\left[\mathrm{g} \mathrm{L}^{-1} \mathrm{~h}^{-1}\right]\end{array}$} & \multicolumn{3}{|c|}{$\begin{array}{c}\text { Concentración } \\
{\left[\mathrm{g} \mathrm{L}^{-1}\right]}\end{array}$} & \multirow[t]{2}{*}{ Referencias } \\
\hline & & & Butirato & Lactato & Acetato & \\
\hline Glucosa & 6 & 1.45 & 53 & & 4.7 & \multirow{4}{*}{ [120] } \\
\hline Fructosa & 6 & 2.56 & 49 & & 1.9 & \\
\hline Sacarosa & 6 & 2.43 & 45 & & 3.1 & \\
\hline Melaza & 6 & & 26 & & 4 & \\
\hline Glucosa & 6 & 6.5 & 44 & & & \multirow{2}{*}{ [117] } \\
\hline Xilosa & 6 & 2.32 & 37 & & & \\
\hline Xilosa & 5 & 0.02 & 5.3 & 33 & 25 & \multirow{5}{*}{ [121] } \\
\hline Xilosa & 5.3 & 1.15 & 28 & 13 & 25 & \\
\hline Xilosa & 5.7 & 1.42 & 41 & 11.2 & 23 & \\
\hline Xilosa & 6 & 1.45 & 37 & 0.5 & 4.9 & \\
\hline Xilosa & 6.3 & 2.2 & 58 & 1 & 8.4 & \\
\hline Glucosa & 6 & 1.23 & 43 & 3.7 & & \multirow{2}{*}{ [122] } \\
\hline Xilosa & 6 & 2.08 & 42 & 1.6 & & \\
\hline
\end{tabular}

Fuente: Elaboración propia.

Las condiciones de operación usadas para alcanzar este desempeño fueron: temperatura de $35^{\circ} \mathrm{C}, \mathrm{pH}$ de 4.3 , velocidad de dilución de 0.9 h-1, y concentración de glucosa 54 gL-1 y de butirato de 3 gL-1 [69]. No obstante, son alcanzadas bajas conversiones de glucosa $(0.31)$ y butirato $(0.19)$ y concentraciones de butirato de 5.1 gL-1. 
En otro trabajo, se logró una productividad ABE de 9.73 g L-1 h1 con adición de ácido butírico $(10 \mathrm{~g} \mathrm{~L}-1)$ y glucosa $(20 \mathrm{~g} \mathrm{~L}-1)$ en un sistema con recirculación de biomasa [71]. El microrganismo usado fue Clostridium saccharoperbutylacetonicum N1-4. La selectividad de butanol hacia los solventes de este microrganismo fue aumentada de 0.666 a 0.797 g-1g-1 con la adición del ácido butírico.

\section{c) Producción biológica de ácido láctico}

El ácido láctico se produce de manera principal por vía bioquímica, solo el $10 \%$ del ácido láctico del mundo es producido usando la ruta de hidrólisis de lactonitrilo [123]. La concentración de producto y productividad usando diferentes microorganismos y sustratos puede ser observada en la Tabla 4. En la selección de un microorganismo para la síntesis de ácido láctico se desea que sea termófilo, que tenga la capacidad de convertir diferentes sustratos con bajo suplemento de nutrientes, que produzca una baja cantidad de subproductos y que alcance altas productividades y rendimientos a bajos niveles de $\mathrm{pH}$ [124]. En la fermentación homoláctica se puede generar lugar otros ácidos si se usan bajas concentraciones de glucosa o si se usan azúcares diferentes a la glucosa como sustrato.

Tabla 4: Concentración de producto y productividad de ácido láctico con diferentes sustratos y microrganismos.

\begin{tabular}{|c|c|c|c|c|}
\hline Microrganismo & Sustrato & $\begin{array}{l}\text { Productividad } \\
{\left[\mathrm{gL}^{-1} \mathrm{~h}^{-1}\right]}\end{array}$ & $\begin{array}{c}\text { Concentración } \\
{\left[\mathrm{gL}^{-1}\right]}\end{array}$ & Ref. \\
\hline $\begin{array}{c}\text { Lactobacillus } \\
\text { delbrueckii NCIM } \\
2365 \text { mutante } \\
\text { Uc-3 }\end{array}$ & Melaza & 3.3 & 120 & [125] \\
\hline $\begin{array}{l}\text { Enterococcus } \\
\text { faecalis RKY1 }\end{array}$ & Melaza & $4-4.3$ & $65-96$ & [129] \\
\hline $\begin{array}{c}\text { Lb.delbrueckii sp. } \\
\text { Delbrueckii }\end{array}$ & Glucosa & 5.5 & 87 & [126] \\
\hline $\begin{array}{l}\text { Lactobacillus } \\
\text { rhamnosus }\end{array}$ & Glucosa & 8.18 & & [128] \\
\hline $\begin{array}{l}\text { Lb. rhamnosus } \\
\text { CECT- } 288\end{array}$ & $\begin{array}{c}\text { Fructosa } \\
\text { Sacaros } \\
\text { a } \\
\text { Tusas de } \\
\text { maíz }\end{array}$ & $\begin{array}{c}5.5 \\
6.2 \\
0.13\end{array}$ & $\begin{array}{c}94 \\
85 \\
111\end{array}$ & [127] \\
\hline $\begin{array}{l}\text { Enterococcus } \\
\text { faecalis Rky1 }\end{array}$ & $\begin{array}{l}\text { Cebada/ } \\
\text { Harina } \\
\text { de } \\
\text { Cebada }\end{array}$ & $0.88-3.8$ & 103 & [130] \\
\hline
\end{tabular}

Fuente: Elaboración propia.

A nivel industrial, el microrganismo más usado es Lactobacillus delbrueckiim. Este microrganismo tiene una temperatura óptima de crecimiento de $41.5^{\circ} \mathrm{C}$, lo cual logra disminuir los costos asociados al enfriamiento, la esterilización, así como la contaminación microbiológica [131]. La síntesis de ácido láctico tiene un mayor rendimiento que la del ácido butírico con rendimientos cercanos al 100. Adicionalmente, a productividades máximas, alrededor de $6 \mathrm{~g} \mathrm{~L}$ 1 h-1 (Tabla 3 y 4), la concentración de producto en la fermentación láctica es dos veces mayor a la de producción de ácido butírico.

\section{CONCLUSIONES}

La fermentación $\mathrm{ABE}$ usando reactores convencionales (lote y reactores operados en continuo y en serie) tiene baja concentración de producto, rendimiento y productividad. Adicionalmente, los costos asociados a la recuperación son altos debido a esa baja concentración de producto y concentración de sustrato alimentadas al reactor. Con el fin de incrementar el desempeño de la fermentación se han explorado diferentes tecnologías, las cuales fueron descritas en detalle en este review. Volver económica la producción de butanol es todo un reto, y por ello se necesitan una combinación de tecnologías eficientes que garanticen una producción económica y estable. Por ello, una tecnología ideal deberá combinar el uso de sistemas de reacción en serie con la recuperación in situ, con el suplemento de ácidos y el uso de sustratos de bajo costo, tales como los residuos lignocelulósicos. Esquemas de reacción producción previa de ácido láctico por Lactobacillus delbrueckii son deseados por que se aumenta el rendimiento, productividad y concentración de butanol. Esta fermentación es preferida porque tiene una concentración de producto mayor, y alcanza rendimientos cercanos al $100 \%$.

Las tecnologías de recuperación in situ más interesantes son sistemas extractivos con solventes o usando evaporación a vacío. La extracción in situ usando pertracción es prometedora porque no es tóxica para el microorganismo y por sus bajos requerimientos de energía ( $8 \mathrm{MJ} / \mathrm{kg}$ ). Adicionalmente, sistemas de extracción por solventes pueden separar y permitir la purificación de inhibidores generados en el petratamiento de residuos lignocelulósicos (furfural y compuestos fenólicos), lo cual es una ventaja importante debido al alto valor comercial de estos productos. Por otro lado, sistemas de evaporación a vacío también han logrado disminuir sus requerimientos energéticos hasta $7 \mathrm{MJ} / \mathrm{kg}$. Lo cual si se suma a su simplicidad hace de esta tecnología, una de las opciones más interesantes.

\section{REFERENCIAS}

[1] D.T. Jones y D.R. Woods, "Acetone-butanol fermentation revisited," Microbiol. Rev., vol. 50, no. 4, pp. 484-524, Dec. 1986.

[2] M. Karimi-Alavijeh y K. Karimi, "Biobutanol production from corn stover in the US," Ind. Crops Prod., vol. 129, no. December 2018, pp. 641-653, Mar. 2019, doi: 10.1016/j.indcrop.2018.12.054.

[3] Y. Ni y Z. Sun, "Recent progress on industrial fermentative production of acetone-butanol-ethanol by Clostridium acetobutylicum in China," Appl. Microbiol. Biotechnol, vol. 83, no. 3, pp. 415-423, Jun. 2009, doi: 10.1007/s00253-009-2003y.

[4] V.V Zverlov, O. Berezina, G.A. Velikodvorskaya, y W.H. Schwarz, "Bacterial acetone and butanol production by industrial fermentation in the Soviet Union: use of hydrolyzed agricultural waste for biorefinery", Appl. Microbiol. Biotechnol, vol. 71, no. 5, pp. 587-97, Aug. 2006.

[5] H. Blaschek y T. Ezeji, "Production of Acetone AcetoneButanol Butanol-Ethanol (ABE) using distillers dried grains with solubles (DDGS): Pentose sugar utilization and impact of degradation products," in GROWING THE BIOECONOMY: SCIENCE AND POLICY FOR NEXT GENERATION BIOREFINING, 2007.

[6] T. Ezeji y H.P. Blaschek, "Fermentation of dried distillers' grains and solubles (DDGS) hydrolysates to solvents and valueadded products bysolventogenic clostridia," Bioresour. Technol., no. 99, pp. 5232-5242., 2008.

[7] T. Ezeji, N. Qureshi, y H.P. Blaschek, "Butanol production from agricultural residues: Impact of degradation products on Clostridium beijerinckii growth and butanol fermentation," Biotechnol. Bioeng, vol. 97, no. 6, pp. 1460-9, Aug. 2007, doi: 10.1002/bit.21373.

[8] A.K.D.S. Abud y C.E.D.F. Silva, "Bioethanol in Brazil: Status, Challenges and Perspectives to Improve the Production," Bioethanol Prod. from Food Crop., pp. 417-443, 2019, doi: 10.1016/B978-0-12-813766-6/00021-7.

[9] J. Zheng, Y. Tashiro, Q. Wang, K. Sakai, y K. Sonomoto, "Feasibility of acetone-butanol-ethanol fermentation from 
eucalyptus hydrolysate without nutrients supplementation," Appl. Energy, vol. 140, pp. 113-119, Feb. 2015, doi: 10.1016/j.apenergy.2014.11.037.

[10] J. Nolling et al., "Genome Sequence and Comparative Analysis of the Solvent-Producing Bacterium Clostridium acetobutylicum,” J. Bacteriol., vol. 183, no. 16, pp. 4823-4838, 2001.

[11] M. Gottwald y G. Gottschalk, "The internal pH of Clostridium acetobutylicum and its effect on the shift from acid to solvent formation," Arch. Microbiol, vol. 143, pp. 42-46, 1985.

[12] D.R. Woods, "The genetic engineering of microbial solvent production," Trends Biotechnol, vol. 13, pp. 259-264, 1995.

[13] L.K. Bowles y W.L. Ellefson, "Effects of butanol on Clostridium acetobutylicum,” Appl. Environ. Microbiol, vol. 50, no. 5, pp. 1165-70, Nov. 1985.

[14] E.J. Steen et al., "Metabolic engineering of Saccharomyces cerevisiae for the production of n-butanol.," Microb. Cell Fact., vol. 7, p. 36, Jan. 2008, doi: 10.1186/1475-2859-7-36.

[15] J. Winkler y K.C. Kao, "Transcriptional Analysis of Lactobacillus brevis to N-Butanol and Ferulic Acid Stress Responses," PLoS One, vol. 6, no. 8, p. e21438, Aug. 2011, doi: 10.1371/journal.pone.0021438.

[16] O.V Berezina, N.V Zakharova, A. Brandt, S.V Yarotsky, W.H. Schwarz, y V.V Zverlov, "Reconstructing the clostridial nbutanol metabolic pathway in Lactobacillus brevis.," Appl. Microbiol. Biotechnol, vol. 87, no. 2, pp. 635-46, Jun. 2010, doi: 10.1007/s00253-010-2480-z.

[17] A. Baez, K.M. Cho, y J.C. Liao, "High-flux isobutanol production using engineered Escherichia coli: a bioreactor study with in situ product removal," Appl. Microbiol. Biotechnol, vol. 90, no. 5, pp. 1681-90, Jun. 2011, doi: 10.1007/s00253-0113173-y.

[18] C.R. Shen, E.I. Lan, Y. Dekishima, A. Baez, K.M. Cho y J.C. Liao, "Driving forces enable high-titer anaerobic 1-butanol synthesis in Escherichia coli.," Appl. Environ. Microbiol, vol. 77, no. 9, pp. 2905-15, May 2011, doi: 10.1128/AEM.0303410.

[19] L.H. Reyes, M.P. Almario, y K.C. Kao, "Genomic library screens for genes involved in n-butanol tolerance in Escherichia coli.," PLoS One, vol. 6, no. 3, p. e17678, Jan. 2011, doi: 10.1371/journal.pone.0017678.

[20] M. Inui, M. Suda, y S. Kimura, "Expression of Clostridium acetobutylicum butanol synthetic genes in Escherichia coli," Appl. Microbiol., vol. 8052, pp. 1305-1316, 2008, doi: 10.1007/s00253-007-1257-5.

[21] J. Winkler, M. Rehmann, y K.C. Kao, "Novel Escherichia coli hybrids with enhanced butanol tolerance", Biotechnol. Lett., Mar. 2010, doi: 10.1007/s10529-010-0247-3.

[22] S. Atsumi et al., "Metabolic engineering of Escherichia coli for 1-butanol production," Metab. Eng., vol. 10, no. 6, pp. 305-11, Nov. 2008, doi: 10.1016/j.ymben.2007.08.003.

[23] J. Rühl, A. Schmid, y L.M. Blank, "Selected Pseudomonas putida strains able to grow in the presence of high butanol concentrations.," Appl. Environ. Microbiol, vol. 75, no. 13, pp. 4653-6, Jul. 2009, doi: 10.1128/AEM.00225-09.

[24] D.R. Nielsen et al., "Engineering alternative butanol production platforms in heterologous bacteria," Metab. Eng., vol. 11, no. 45, pp. 262-73, 2009, doi: 10.1016/j.ymben.2009.05.003.

[25] N. Kataoka, T. Tajima, J. Kato, W. Rachadech y A.S. Vangnai, "Development of butanol-tolerant Bacillus subtilis strain GRSW2-B1 as a potential bioproduction host," AMB Express, vol. 1, no. 1, p. 10, 2011, doi: 10.1186/2191-0855-1-10.

[26] E.M. Green, "Fermentative production of butanol-the industrial perspective," Curr. Opin. Biotechnol., vol. 22, no. 3, pp. 337-343, Jun. 2011, doi: 10.1016/j.copbio.2011.02.004.
[27] Butamax, "California Biobutanol Multimedia Evaluation. http://www.arb.ca.gov/fuels/multimedia/020910biobutanoltierI. pdf," 2010.

[28] N. Qureshi, A. Lolas, y H.P. Blaschek, "Soy molasses as fermentation substrate for production of butanol using Clostridium beijerinckii BA101.,’ J. Ind. Microbiol. Biotechnol, vol. 26, no. 5, pp. 290-295, 2001, doi: 10.1038/sj.jim.7000131.

[29] N. Qureshi y H.P. Blaschek, "ABE production from corn: a recent economic evaluation," J. Ind. Microbiol. Biotechnol, vol. 27, no. 5, pp. 292-7, Nov. 2001, doi: 10.1038/sj/jim/7000123.

[30] N. Qureshi y H.P. Blaschek, "Evaluation of recent advances in butanol fermentation, upstream, and downstream processing," Bioprocess Biosyst. Eng., vol. 24, no. 4, pp. 219-226, Nov. 2001.

[31] P.A.M. Claassen, M.A.W. Budde, A.M. López-Contreras, Â.P. A.M. Claassen, y A.M. Lo, "Utilisation of saccharides in extruded domestic organic waste by Clostridium acetobutylicum ATCC 824 for production of acetone, butanol and ethanol," vol. 54, pp. 162-167, 2000.

[32] A.M. López-Contreras, P.A.M. Claassen, M.A.W. Budde, y A.M. López-Contreras, "Acetone , Butanol and Ethanol Production from Domestic Organic Waste by Solventogenic Clostridia," J. Mol. Microbiol. Biotechnol., vol. 2, no. 1, pp. 39 44, 2000.

[33] R. Koukiekolo, H. Cho, A. Kosugi, M. Inui, H. Yukawa, y R.H. Doi, "Degradation of Corn Fiber by Clostridium cellulovorans Cellulases and Hemicellulases and Contribution of Scaffolding Protein CbpA," vol. 71, no. 7, pp. 3504-3511, 2005, doi: 10.1128/AEM.71.7.3504.

[34] T. Ezeji, N. Qureshi, y H. Blaschek, "Production of acetonebutanol-ethanol (ABE) in a continuous flow bioreactor using degermed corn and Clostridium beijerinckii," Process Biochem., vol. 42, no. 1, pp. 34-39, Jan. 2007.

[35] N. Qureshi, B.C. Saha, B. Dien, R.E. Hector, y M.A. Cotta, "Production of butanol (a biofuel) from agricultural residues: Part I - Use of barley straw hydrolysate," Biomass and Bioenergy, vol. 34, no. 4, pp. 559-565, Apr. 2010.

[36] R. Marchal, M. Ropars, y J.P. Vandescasteele, "CONVERSION INTO ACETONE AND BUTANOL OF LIGNOCELLULOSIC SUBSTRATES PRETREATED BY STEAM EXPLOSION," Biotechno!ogy Lett., vol. 8, no. 5, pp. 365-370, 1986.

[37] C.E. Voget, C.F. Mignone, y R.J. Ertola, "Butanol production from apple pomance,” Biotechnol. Lett, vol. 7, pp. 43-46, 1985.

[38] T.W. Jesse, T.C. Ezeji, N. Qureshi, y H.P. Blaschek, "Production of butanol from starch-based waste packing peanuts and agricultural waste," J. Ind. Microbiol. Biotechnol., vol. 29, no. November 2001, pp. 117-123, 2002, doi: 10.1038/sj.jim.7000285.

[39] N.A. Gutierrez, S. Maddoxt, K.C. Schuster, H. Swoboda, y J.R. Gapes, "Strain comparison and medium preparation for the acetone-butanol-ethanol (ABE) fermentation process using a substrate of potato," Bioresour. Technol., vol. 66, no. 3, pp. 263 265, Dec. 1998.

[40] J.C. Andrade y I. Vasconcelos, "Continuous cultures of Clostridium acetobutylicum: culture stability and low-grade glycerol utilisation.," Biotechnol. Lett., vol. 25, no. 2, pp. 1215, Jan. 2003.

[41] R. Marchal, D. Blanchet, y J.P. Vandecasteele, "Industrial optimization of acetone-butanol fermentation: a study of the utilization of Jerusalem artichokes," Appl. Microbiol. Biotechnol., vol. 23, no. 2, pp. 92-98, Dec. 1985, doi: 10.1007/BF00938959.

[42] R. Harun, M. Singh, G.M. Forde, y M.K. Danquah, "Bioprocess engineering of microalgae to produce a variety of consumer products,” Renew. Sustain. Energy Rev., vol. 14, no. 3, pp. 
1037-1047, Apr. 2010.

[43] J.P. Nakas, M. Schaedle, C.M. Parkinson, C.E. Coonley y S.W. Tanenbaum, "System development for linked-fermentation production of solvents from algal biomass.," Appl. Environ. Microbiol., vol. 46, no. 5, pp. 1017-23, Nov. 1983.

[44] C. Chen y H. Blaschek, "Acetate enhances solvent production and prevents degeneration in Clostridium beijerinckii BA101," Appl. Microbiol. Biotechnol., vol. 52, no. 2, pp. 170-3, Aug. 1999.

[45] J. Formanek, R. Mackie, y H.P. Blaschek, "Enhanced Butanol Production by Clostridium beijerinckii BA101 Grown in Semidefined P2 Medium Containing 6 Percent Maltodextrin or Glucose.," Appl. Environ. Microbiol., vol. 63, no. 6, pp. 2306 10, Jun. 1997.

[46] C. Xue, X.-Q. Zhao, C.G. Liu, L.J. Chen, y F.W. Bai, "Prospective and development of butanol as an advanced biofuel.," Biotechnol. Adv., vol. 31, no. 8, pp. 1575-84, Dec. 2013, doi: 10.1016/j.biotechadv.2013.08.004.

[47] V.H. Grisales-Díaz, M.J. Willis, M. von-Stosch, G.O. Tost, y O. Prado-Rubio, "Assessing the energy requirements for butanol production using fermentation tanks-in-series operated under vacuum," Renew. Energy, Jul. 2020, doi: 10.1016/j.renene.2020.07.039.

[48] A.P. Mariano, T.C. Ezeji, y N. Qureshi, "Chapter 4. Butanol Production by Fermentation: Efficient Bioreactors," in Commercializing Biobased Products: Opportunities, Challenges, Benefits, and Risks, no. 43, S. W. Snyder, Ed. Cambridge: Royal Society of Chemistry, 2015, pp. 48-70.

[49] A.S. Afschar, H. Biebl, K. Schaller, K. Schiigerl, y K. Schrugerl, "Production of acetone and butanol by Clostridium acetobutylicum in continuous culture with cell recycle," Appl Microbiol Biotechnol, vol. 22, no. 6, pp. 394-398, 1985.

[50] X. Yang y G.T. Tsao, "Enhanced acetone-butanol fermentation using repeated fed-batch operation coupled with cell recycle by membrane and simultaneous removal of inhibitory products by adsorption.," Biotechnol. Bioeng., vol. 47, no. 4, pp. 444-50, Aug. 1995.

[51] N. Qureshi, J. Schripsema, J. Lienhardt, y H.P. Blaschek, "Continuous solvent production by Clostridium beijerinckii BA101 immobilized by adsorption onto brick," World J. Microbiol. Biotechnol., vol. 16, pp. 337-382, 2000.

[52] Y. Tashiro, K. Takeda, G. Kobayashi, y K. Sonomoto, "High production of acetone-butanol-ethanol with high cell density culture by cell-recycling and bleeding," J. Biotechnol., vol. 120, no. 2, pp. 197-206, 2005.

[53] J. Lienhardt, J. Schripsema, N. Qureshi, y H.P. Blaschek, "Butanol production by Clostridium beijerinckii BA101 in an immobilized cell biofilm reactor," Appl. Biochem. Biotechnol., vol. 98, no. 1, pp. 591-598, 2002.

[54] H. Bahl, W. Andersch, y G. Gottschalk, "Continuous production of acetone and butanol by Clostridium acetobutylicum in a twostage phosphate limited chemostat," Eur. J. Appl. Microbiol. Biotechnol., vol. 15, no. 4, pp. 201-205, 1982.

[55] J.A. Phillips y A.E. Humphrey, "Process technology for the biological conversion of lignocellulosic materials to fermentables and alcohols," in In Wood and agricultural residues: research on use for feed, fuels and chemicals, Soltes, Ac., New York, 1983.

[56] V.H. Grisales-Díaz y G. Olivar-Tost, "Techno-economic analysis of extraction-based separation systems for acetone, butanol, and ethanol recovery and purification," Bioresour. Bioprocess., vol. 4, no. 1, p. 12, Dec. 2017, doi: 10.1186/s40643017-0142-z.

[57] N. Qureshi, M.M. Meagher, y R.W. Hutkins, "Recovery of butanol from model solutions and fermentation broth using a silicalite/silicone membrane," J. Memb. Sci., vol. 158, no. 1-2, pp. 115-125, Jun. 1999, doi: 10.1016/S0376-7388(99)00010-1.

[58] N. Qureshi y H. Blaschek, "Butanol production using Clostridium beijerinckii BA101 hyper-butanol producing mutant strain and recovery by pervaporation," Appl. Biochem. Biotechnol., vol. 84, no. 4, pp. 225-235, 2000.

[59] T.C. Ezeji, N. Qureshi, y H.P. Blaschek, "Production of butanol by Clostridium beijerinckii BA101 and in-situ recovery by gas stripping," Microbiol. Biotechnol. World J, vol. 19, pp. 595603., 2003.

[60] T.C. Ezeji, N. Qureshi, y H.P. Blaschek, "Butanol fermentation research: Upstream and downstream manipulations," Chem Rec, vol. 4, pp. 305-314, 2004.

[61] T.C. Ezeji, N. Qureshi y H.P. Blaschek, "Acetone-butanol ethanol (ABE) production from concentrated substrate: Reduction in substrate inhibition by fed-batch technique and product inhibition by gas stripping," Appl Microbiol Biotechnol, vol. 63, pp. 653-658., 2004.

[62] G. Eckert, K. Schügerl, y K. Schiigerl, "Continuous acetonebutanol production with direct product removal," Appl. Microbiol. Biotechnol., vol. 27, no. 3, pp. 221-228, Dec. 1987.

[63] N. Qureshi y I. Maddox, "Reduction in Butanol Inhibition by Perstraction: Utilization of Concentrated Lactose/Whey Permeate by Clostridium acetobutylicum to Enhance Butanol Fermentation Economics," Food Bioprod. Process., vol. 83, no. 1, pp. 43-52, Mar. 2005.

[64] N. Qureshi, I.S. Maddox, y A. Friedl, "Application of continuous substrate feeding to the ABE fermentation: relief of product inhibition using extraction, perstraction, stripping, and pervaporation," Biotechnol. Prog., vol. 8, no. 5, pp. 382-390, Sep. 1992.

[65] P. Pierrot, M. Fick, y J. M. Engasser, "Continuous acetonebutanol fermentation with high productivity by cell ultrafiltration and recycling," Biotechnol. Lett., vol. 8, no. 4, pp. 253-256, Apr. 1986.

[66] C. Frick, K. Schügerl, y K. Schiigerl, "Continuous acetonebutanol production with free and immobilized Clostridium acetobutylicum," Appl. Microbiol. Biotechnol., vol. 25, no. 3, pp. 186-193, Dec. 1986.

[67] C.H. Park, M.R. Okos, y P.C. Wankat, "Acetone-butanolethanol (ABE) fermentation and simultaneous separation in a trickle bed reactor," Biotechnol. Prog., vol. 7, no. 2, pp. 185194, Mar. 1991.

[68] D.E. Ramey, "Continuous two stage, dual path anaerobic fermentation of butanol and other organic solvents using two different strains of bacteria," 5753474, 1998.

[69] W.C. Huang, D.E. Ramey y S. Yang, "Continuous production of butanol by clostridium acetobutylicum immobilized in a fibrous bed bioreactor," Appl. Biochem. Biotechnol., vol. 115, pp. 887898, 2004.

[70] Y. Zhang, Y. Ma, F. Yang, y C. Zhang, "Continuous acetonebutanol-ethanol production by corn stalk immobilized cells.," J. Ind. Microbiol. Biotechnol., vol. 36, no. 8, pp. 1117-1121, Aug. 2009.

[71] S.I. Baba, Y. Tashiro, H. Shinto, y K. Sonomoto, "Development of high-speed and highly efficient butanol production systems from butyric acid with high density of living cells of Clostridium saccharoperbutylacetonicum.," J. Biotechnol., pp. 4-11, Jun. 2011.

[72] N. Qureshi y H.P. Blaschek, "Recovery of butanol from fermentation broth by gas stripping," Biotechnol. Bioeng., vol. 22, pp. 557-564, 2001.

[73] W. J. Groot, H.S. Soedjak, P.B. Donck, R.G.J.M. Lans, K.C.A.M. Luyben, y J.M.K. Timmer, "Butanol recovery from fermentations by liquid-liquid extraction and membrane solvent 
extraction,” Bioprocess Eng., vol. 5, no. 5, pp. 203-216, 1990.

[74] A. Ishizaki, "Extractive acetone-butanol-ethanol fermentation using methylated crude palm oil as extractant in batch culture of Clostridium saccharoperbutylacetonicum N1-4 (ATCC 13564)," J. Biosci. Bioeng., vol. 87, no. 3, pp. 352-356, Jan. 1999.

[75] G.A. Janke y W.D. Johnson, Jr., "Extractive fermentation using convoluted fibrous bed bioreactor," 5563069, 1999.

[76] S.R. Roffler, H.W. Blanch, y C.R. Wilke, "In-situ recovery of butanol during fermentation," Bioprocess Eng., vol. 2, no. 4, pp. 181-190, 1987.

[77] C. Job, C. Schertler, W.L. Staudenbauer, y E. Blass, "Selection of organic solvents for in situ extraction of fermentation products from Clostridium thermohydrosulfuricum cultures," Biotechnol. Tech., vol. 3, no. 5, pp. 315-320, May 1989.

[78] B.H. Davison y J.E. Thompson, "Continuous direct solvent extraction of butanol in a fermenting fluidized-bed bioreactor with immobilized Clostridium acetobutylicum," Appl. Biochem. Biotechnol., vol. 39-40, no. 1, pp. 415-426, Sep. 1993.

[79] S.H. Lee et al., "Ex situ product recovery for enhanced butanol production by Clostridium beijerinckii," Bioprocess Biosyst. Eng., vol. 39, no. 5, pp. 695-702, 2016, doi: 10.1007/s00449016-1550-8.

[80] K. Kraemer, A. Harwardt, R. Bronneberg, y W. Marquardt, "Separation of butanol from acetone-butanol-ethanol fermentation by a hybrid extraction-distillation process," Comput. Chem. Eng., vol. 35, no. 5, pp. 949-963, May 2011, doi: 10.1016/j.compchemeng.2011.01.028.

[81] T.C. Ezeji, N. Qureshi, P. Karcher, y H.P. Blaschek, "Production of Butanol from Corn," in Alcoholic Fuels, 2006.

[82] R. Shukla, W. Kang y K.K. Sirkar, "Toxicity of organic solvents toclostridium acetobutylicum for extractive ABE fermentation," Appl. Biochem. Biotechnol., vol. 18, no. 1, pp. 315-324, 1988, doi: 10.1007/BF02930835.

[83] A. Leo, C. Hansch, y D. Elkins, "Partition coefficients and their uses," Chem. Rev., vol. 71, no. 6, pp. 525-616, Dec. 1971.

[84] S.H. Ha, N.L. Mai, y Y.M. Koo, "Butanol recovery from aqueous solution into ionic liquids by liquid-liquid extraction," Process Biochem., vol. 45, no. 12, pp. 1899-1903, Dec. 2010.

[85] L.D. Simoni, A. Chapeaux, J.F. Brennecke, y M.A. Stadtherr, "Extraction of biofuels and biofeedstocks from aqueous solutions using ionic liquids," Comput. Chem. Eng., vol. 34, no. 9, pp. 1406-1412, Feb. 2010, doi: 10.1016/j.compchemeng.2010.02.020.

[86] H. González-Peñas, T. a. Lu-Chau, M.T. Moreira, y J.M. Lema, "Solvent screening methodology for in situ ABE extractive fermentation," Appl. Microbiol. Biotechnol., vol. 98, no. 13, pp. 5915-5924, 2014, doi: 10.1007/s00253-014-5634-6.

[87] D.R. Lide, Ed., CRC Handbook of Chemistry and Physics, CRC Press/. Boca Raton, 2008.

[88] V.H. Grisales-Díaz y G. Olivar-Tost, "Economic optimization of in situ extraction of inhibitors in acetone-ethanol-butanol (ABE) fermentation from lignocellulose," Process Biochem., vol. 70, pp. 1-8, Jul. 2018, doi: 10.1016/j.procbio.2018.04.014.

[89] V. Outram, C.A. Lalander, J.G.M. Lee, E.T. Davis, y A.P. Harvey, "A comparison of the energy use of in situ product recovery techniques for the acetone butanol ethanol fermentation," Bioresour. Technol., vol. 220, pp. 590-600, Nov. 2016, doi: 10.1016/j.biortech.2016.09.002.

[90] N. Qureshi, S. Hughes, I.S. Maddox, y M.A. Cotta, "Energyefficient recovery of butanol from model solutions and fermentation broth by adsorption," Bioprocess Biosyst. Eng., vol. 27, no. 4, pp. 215-222, Jul. 2005, doi: 10.1007/s00449-0050402-8.

[91] M. Holtzapple, "Conceptual design for a process to recover volatile solutes from aqueous solutions using silicalite," Sep. Technol., vol. 4, no. 4, pp. 213-229, Oct. 1994.

[92] N.B. Milestone y D.M. Bibby, "Concentration of alcohols by adsorption on silicalite," J. Chem. Technol. Biotechnol., vol. 31, no. 1, pp. 732-736, May 1981, doi: 10.1002/jctb.503310198.

[93] A. Oudshoorn, L.A.M. van-der-Wielen, y A.J.J. Straathof, "Assessment of Options for Selective 1-Butanol Recovery from Aqueous Solution,” Ind. Eng. Chem. Res., vol. 48, no. 15, pp. 7325-7336, Aug. 2009, doi: 10.1021/ie900537w.

[94] W.J. Groot y K.C.A.M. Luyben, "In situ product recovery by adsorption in the butanol / isopropanol batch fermentation," Appl Microbiol Biotechnol, vol. 25, pp. 29-31, 1986.

[95] K. Das, B. Soni, y T. Chose, "Static and column studies on selective adsorption-desorption of butanol.," in Proceedings 4th European congress on biotechnol, 1987, pp. 1:76-78.

[96] L. Nielsen, M. Larsson, O. Holst, y B. Mattiasson, “Adsorbents for extractive bioconversion applied to the acetone-butanol fermentation," Appl. Microbiol. Biotechnol., vol. 28, no. 4-5, pp. 335-339, Jun. 1988, doi: 10.1007/BF00268191.

[97] X. Yang, G.J. Tsai, y G.T. Tsao, "Enhancement of in situ adsorption on the acetone-butanol fermentation by Clostridium acetobutylicum," Sep. Technol., vol. 4, no. 2, pp. 81-92, Apr. 1994.

[98] J.J. Kipling y D.B. Peakall, "Adsorption from binary liquid mixtures on silica and titania gels," J. Chem. Soc., p. 4054, 1957.

[99] M. Meagher, N. Qureshi, y R. Hutkins, "Silicalite membrane and method for the selective recovery and concentration of acetone and butanol from model ABE solutions and fermentation broth," 5755967, 1998.

[100] E. Favre, Q.T. Nguyen, S. Bruneau, y M.S. Loing, "Extraction of 1 -Butanol from Aqueous Solutions by Pervaporation," vol. 65, pp. 221-228, 1996.

[101] J. Huang y M.M.M. Meagher, "Pervaporative recovery of nbutanol from aqueous solutions and $\mathrm{ABE}$ fermentation broth using thin-film silicalite-filled silicone composite membranes," J. Memb. Sci., vol. 192, no. 1-2, pp. 231-242, Oct. 2001.

[102] W.J. Groot', C.E. Qever, y N.W.F. Kossen, "Pervaporation for simultaneous product recovery in the butanol/isopropanol batch fermentation," Biotechnol. Lett., vol. 6, no. 11, pp. 709-714, 1984, doi: 10.1007/BF00133061.

[103] N. Qureshi, M.M. Meagher, J. Huangb, y R.W. Hutkins, "Acetone butanol ethanol (ABE) recovery by pervaporation using silicalite-silicone composite membrane from fed-batch reactor of Clostridium acetobutylicum," J. Memb. Sci., vol. 187, no. 1-2, pp. 93-102, Jun. 2001.

[104] C. Park, "Pervaporative butanol fermentation using a new bacterial strain,” Biotechnol. Bioprocess Eng., vol. 1, pp. 1-8, 1996.

[105] P. Izák, K. Schwarz, W. Ruth, H. Bahl, y U. Kragl, "Increased productivity of Clostridium acetobutylicum fermentation of acetone, butanol, and ethanol by pervaporation through supported ionic liquid membrane.," Appl. Microbiol. Biotechnol., vol. 78, no. 4, pp. 597-602, Mar. 2008.

[106] N. Qureshi y H.P. Blaschek, "Butanol production from agricultural biomass," in Food Biotechnology, Taylor \& F., Boca Raton, 2005.

[107] W.J. Groot, R.G.J.M. van-der-Lans y K.C.A.M. Luyben, "Technologies for butanol recovery integrated with fermentations," Process Biochem., vol. 27, no. 2, pp. 61-75, Mar. 1992, doi: 10.1016/0032-9592(92)80012-R.

[108] L.M. Vane, "A review of pervaporation for product recovery from biomass fermentation processes," J. Chem. Technol. Biotechnol., vol. 80, no. 6, pp. 603-629, Jun. 2005.

[109] V.H. Grisales Díaz y G. Olivar Tost, "Butanol production from lignocellulose by simultaneous fermentation, saccharification, 
and pervaporation or vacuum evaporation," Bioresour. Technol., vol. 218, pp. 174-182, Oct. 2016, doi: 10.1016/j.biortech.2016.06.091.

[110] J.P.C. Pereira et al., "Integrated Vacuum Stripping and Adsorption for the Efficient Recovery of (Biobased) 2-Butanol," Ind. Eng. Chem. Res., vol. 58, no. 1, pp. 296-305, Jan. 2019, doi: 10.1021/acs.iecr.8b03043.

[111] V.H. Grisales-Díaz, M. von-Stosch, y M.J. Willis, "Butanol production via vacuum fermentation: An economic evaluation of operating strategies," Chem. Eng. Sci., vol. 195, pp. 707-719, Feb. 2019, doi: 10.1016/j.ces.2018.10.016.

[112] A.P. Mariano, N. Qureshi, R. Maciel-Filho, y T.C. Ezeji, "Assessment of in situ butanol recovery by vacuum during acetone butanol ethanol (ABE) fermentation," J. Chem. Technol. Biotechnol., vol. 87, no. 3, pp. 334-340, Mar. 2012, doi: $10.1002 /$ jctb. 2717.

[113] D. Ramey, "Production of Butyric Acid and Butanol from Biomass", Morgantown, WV, 2004.

[114] G. Matta-el-Ammouri, R. Janati-Idrissi, a M. Junelles, H. Petitdemange, y R. Gay, "Effects of butyric and acetic acids on acetone-butanol formation by Clostridium acetobutylicum.," Biochimie, vol. 69, no. 2, pp. 109-15, Feb. 1987.

[115] M. Oshiro, K. Hanada, Y. Tashiro, y K. Sonomoto, "Efficient conversion of lactic acid to butanol with $\mathrm{pH}$-stat continuous lactic acid and glucose feeding method by Clostridium saccharoperbutylacetonicum.," Appl. Microbiol. Biotechnol., vol. 87, no. 3, pp. 1177-85, Jul. 2010.

[116] P. Rogers, J. Chen, y M. J. O. Zidwick, The Prokaryotes. Springer New York, 2006.

[117] Y. Zhu, Z. Wu, y S.T. Yang, "Butyric acid production from acid hydrolysate of corn fibre by Clostridium tyrobutyricum in a fibrous-bed bioreactor," Process Biochem., vol. 38, no. 5, pp. 657-666, Dec. 2002, doi: 10.1016/S0032-9592(02)00162-0.

[118] J. Zigova y E.S, "Butyric acid production by Clostridium butyricum with integrated extraction and pertraction," Biotechnol. Bioeng., vol. 34, pp. 835-843, 1999.

[119] C. Zhang, H. Yang, F. Yang, y Y. Ma, "Current progress on butyric acid production by fermentation.," Curr. Microbiol., vol. 59, no. 6, pp. 656-63, Dec. 2009.

[120] L. Jiang, J. Wang, S. Liang, X. Wang, P. Cen y Z. Xu, "Butyric acid fermentation in a fibrous bed bioreactor with immobilized Clostridium tyrobutyricum from cane molasses," Bioresour. Technol., vol. 100, no. 13, pp. 3403-3409, Jul. 2009, doi: 10.1016/j.biortech.2009.02.032.

[121] Y. Zhu y S.-T. Yang, "Effect of pH on metabolic pathway shift in fermentation of xylose by Clostridium tyrobutyricum.," J. Biotechnol., vol. 110, no. 2, pp. 143-57, May 2004, doi: 10.1016/j.jbiotec.2004.02.006.

[122] J. Huang et al., "Efficient production of butyric acid from Jerusalem artichoke by immobilized Clostridium tyrobutyricum in a fibrous-bed bioreactor.," Bioresour. Technol., vol. 102, no. 4, pp. 3923-6, Mar. 2011.

[123] K. Hofvendahl y B. Hahn-Hägerdal, "Factors affecting the fermentative lactic acid production from renewable resources(1).," Enzyme Microb. Technol., vol. 26, no. 2-4, pp. 87-107, Feb. 2000.

[124] C. Akerberg y G. Zacchi, "An economic evaluation of the fermentative production of lactic acid from wheat flour," Bioresour. Technol., vol. 75, no. 2, pp. 119-126, Nov. 2000.

[125] S.S. Patil, S.R. Kadam, K.B. Bastawde, J.M. Khire y D.V Gokhale, "Production of lactic acid and fructose from media with cane sugar using mutant of Lactobacillus delbrueckii NCIM 2365.," Lett. Appl. Microbiol., vol. 43, no. 1, pp. 53-7, Jul. 2006.

[126] Suskovic J.N.S.M..V. y M.S. "Lactic acid fermentation kinetics on different carbon sources," Prehrambeno-Tehnol Biotehnol Rev, vol. 29, pp. 155-8, 1991.

[127] B. Rivas, A.B. Moldes, J.M. Domínguez, y J.C. Parajó, "Development of culture media containing spent yeast cells of Debaryomyces hansenii and corn steep liquor for lactic acid production with Lactobacillus rhamnosus.," Int. J. Food Microbiol., vol. 97, no. 1, pp. 93-8, Dec. 2004.

[128] G. Min-tian, M. Koide, R. Gotou, H. Takanashi, M. Hirata, y T. Hano, "Development of a continuous electrodialysis fermentation system for production of lactic acid by Lactobacillus rhamnosus," Process Biochem., vol. 40, no. 3-4, pp. 1033-1036, Mar. 2005.

[129] Y. WEE, "Utilization of sugar molasses for economical L(+)lactic acid production by batch fermentation of Enterococcus faecalis," Enzyme Microb. Technol., vol. 35, no. 6-7, pp. 568573, Dec. 2004.

[130] H. Oh, Y.J. Wee, J.S. Yun, S. Ho-Han, S. Jung, y H.W. Ryu, "Lactic acid production from agricultural resources as cheap raw materials.," Bioresour. Technol., vol. 96, no. 13, pp. 1492-8, Sep. 2005.

[131] L. Serna-Cock y A.R. Stouvenel, "Produccion Biotecnologica De Acido Lactico: Estado Del Arte Biotechnological Production of Lactic Acid: State of the Art Produccion Biotecnoloxica De Acido Lactico: Estado Do Arte," CyTA - J. Food, vol. 5, no. 1, pp. 54-65, Dec. 2005, doi: 10.1080/11358120509487672. 